\title{
Insulin resistance in Type 2 (non-insulin-dependent) diabetic patients with hypertriglyceridaemia
}

\author{
E.Widén, A. Ekstrand, C. Saloranta, A. Franssila-Kallunki, J. Eriksson, C.Schalin-Jäntti and L. Groop \\ The Fourth Department of Medicine, Helsinki University Hospital, Helsinki, Finland
}

Summary. Hypertriglyceridaemia, which is frequently seen in Type 2 (non-insulin-dependent) diabetes mellitus, is associated with insulin resistance. The connection between hypertriglyceridaemia and insulin resistance is not clear, but could be due to substrate competition between glucose and lipids. To address this question we measured glucose and lipid metabolism in 39 Type 2 diabetic patients with hypertriglyceridaemia, i.e. mean fasting serum triglyceride level equal to or above $2 \mathrm{mmol} / \mathrm{l}$ (age $59 \pm 1$ years, BMI $27.4 \pm 0.5 \mathrm{~kg} / \mathrm{m}^{2}, \quad \mathrm{HbA}_{1 \mathrm{c}} 8.0 \pm 0.2 \%$, serum triglycerides $3.2 \pm 0.2 \mathrm{mmol} / \mathrm{l}$ ) and 41 Type 2 diabetic patients with normotriglyceridaemia, i.e. mean fasting serum triglyceride level below $2 \mathrm{mmol} / \mathrm{l}$ (age $58 \pm 1$ years, BMI $27.0 \pm 0.7 \mathrm{~kg} / \mathrm{m}^{2}$, $\mathrm{HbA}_{\mathrm{Ic}} 7.8 \pm 0.2 \%$, serum triglycerides $\left.1.4 \pm 0.1 \mathrm{mmol} / \mathrm{l}\right)$. Insulin sensitivity was assessed using a $340 \mathrm{pmol} \cdot\left(\mathrm{m}^{2}\right)^{-1} \cdot \mathrm{min}^{-1}$ euglycaemic insulin clamp. Substrate oxidation rates were measured with indirect calorimetry and hepatic glucose production was estimated using a primed $(25 \mu \mathrm{Ci})$-constant $(0.25 \mu \mathrm{Ci} / \mathrm{min})$ infusion of $\left[3{ }^{3} \mathrm{H}\right]$-glucose. Suppression of lipid oxidation by insulin was impaired in patients with hypertriglyceridaemia vs patients with normal triglyceride levels $\left(3.5 \pm 0.2\right.$ vs $\left.3.0 \pm 0.2 \mu \mathrm{mol} \cdot \mathrm{kg}^{-1} \cdot \mathrm{min}^{-1} ; p<0.05\right)$.
Stimulation of glucose disposal by insulin was reduced in hypertriglyceridaemic vs normotriglyceridaemic patients $\left(27.0 \pm 1.3 \mathrm{vs} 31.9 \pm 1.6 \mu \mathrm{mol} \cdot \mathrm{kg}^{-1} \cdot \mathrm{min}^{-1} ; p<0.05\right)$ primarily due to impaired glucose storage $(9.8 \pm 1.0$ vs $\left.14.6 \pm 1.4 \mu \mathrm{mol} \cdot \mathrm{kg}^{-1} \cdot \mathrm{min}^{-1} ; p<0.01\right)$. In contrast, insulinstimulated glucose oxidation was similar in patients with hypertriglyceridaemia and in patients with normal triglyceride concentrations $\left(16.9 \pm 0.8\right.$ vs $17.2 \pm 0.7 \mu \mathrm{mol} \cdot \mathrm{kg}^{-1}$. $\min ^{-1}$ ). Hepatic glucose production in the basal state and during the clamp did not differ between the two groups. We conclude therefore that oxidative substrate competition between glucose and lipids does not explain insulin resistance associated with hypertriglyceridaemia in Type 2 diabetes. The question remains whether the reduced nonoxidative glucose disposal observed in the patients with hypertriglyceridaemia is genetically determined or a consequence of increased lipid oxidation.

Key words: Hypertriglyceridaemia, insulin resistance, Type 2 (non-insulin-dependent) diabetes mellitus, glucose metabolism, lipid metabolism.
Lipid and lipoprotein abnormalities are common among patients with Type 2 (non-insulin-dependent) diabetes mellitus. Both newly-diagnosed Type 2 diabetic patients and those with established treatment regimens tend to have $50-100 \%$ higher triglyceride levels than control subjects [1-6]. Insulin resistance, primarily due to a defect in the non-oxidative glucose metabolism, is a characteristic feature of Type 2 diabetic patients [7]. However, insulin resistance is also present in non-diabetic subjects with endogenous hypertriglyceridaemia [8-12]. A previous study showed that hypertriglyceridaemia was associated with a reduction in peripheral glucose uptake, whereas the suppressive effect of insulin on hepatic glucose production was intact [12]. Furthermore, hypertriglyceridaemic subjects display resistance to the antilipolytic effect of insulin [11].
The basis for the connection between hypertriglyceridaemia and insulin resistance is not known. As the ability to suppress non-esterified fatty acids (NEFA) by insulin is reduced in hypertriglyceridaemic subjects [11], insulin resistance might be metabolically induced by increased availability of NEFA which might restrain the consumption of glucose. Effective competition between glucose and NEFA was demonstrated in isolated rat hearts and diaphragms by Randle and coworkers almost 30 years ago [13]. Subsequent studies investigating the operation of Randle's cycle have shown that experimental elevation of NEFA in man leads to substrate competition between lipids and glucose, i.e. increased lipid oxidation and decreased glucose oxidation [14-18]. Furthermore, there is accumulating evidence from acute studies suggesting a 
time-dependent suppression of non-oxidative glucose metabolism by increased lipid oxidation $[17,18]$. However, it is not known how chronic hypertriglyceridaemia might influence the intracellular fate of glucose in an insulin resistant state characterized by defective non-oxidative glucose metabolism, such as Type 2 diabetes. Therefore, we have investigated the impact of hypertriglyceridaemia on glucose and lipid metabolism in Type 2 diabetic subjects.

\section{Subjects and methods}

Eighty Type 2 diabetic patients and 17 control subjects without family history of diabetes participated in the study. The diabetic patients were further divided into those with hypertriglyceridaemia (HTG) and those with normal triglycerides (NTG) based on three consecutive measurements of fasting serum(s) triglycerides. The patients were considered hypertriglyceridaemic if their mean s-triglyceride value exceeded or was equal to $2 \mathrm{mmol} / 1$ and as normotriglyceridaemic if the mean s-triglyceride was below $2 \mathrm{mmol} / \mathrm{l}$. The cut-off value of $2 \mathrm{mmol} / 1$ was chosen as the mean value of good and acceptable metabolic control recommended by the European NIDDM policy group [19]. The clinical characteristics of the study groups are shown in Table 1. Twenty-nine of the patients in the HTG group were on oral hypoglycaemic therapy, four were on insulin therapy and six patients were controlled by diet alone. In the NTG group 32 patients were on oral hypoglycaemic therapy, four were on insulin therapy and five patients were controlled by diet alone. None of the patients were taking hypolipaemic medication. Informed consent was obtained from all the subjects and the study protocol was approved by the ethical committee of the Fourth Department of Medicine, Helsinki University Hospital.

Glucose metabolism was assessed by the euglycaemic insulin clamp technique [20]. The clamp was started at 07.30 hours after a $12 \mathrm{~h}$ overnight fast. The patients did not take their normal medication the morning of the clamp. Substrate oxidation rates and energy production were estimated by indirect calorimetry [21]. A primed $(25 \mu \mathrm{Ci})$ - constant infusion of $\left[3{ }^{-3} \mathrm{H}\right]$ glucose was used to assess glucose turnover and hepatic glucose production. After obtaining three basal samples for glucose and insulin, a primed-constant infusion of short-acting human insulin (Actrapid; Novo-Nordisk, Copenhagen, Denmark) was administered at a rate of $340 \mathrm{pmol}\left(\cdot \mathrm{m}^{2}\right)^{-1} \cdot \mathrm{min}^{-1}$. The plasma glucose concentration was determined with 5-min intervals during the clamp and a variable infusion of $20 \%$ of glucose was adjusted to maintain the plasma glucose concentration constant for $120 \mathrm{~min}$ in the control subjects. In the diabetic patients, no glucose was infused until plasma glucose had declined to approximately $6 \mathrm{mmol} / \mathrm{l}$ and had been maintained at that level for $60 \mathrm{~min}$. The clamp lasted for $152 \pm 4 \mathrm{~min}$ in the HTG group and $138 \pm 4$ in the NTG group.

At unchanged plasma glucose concentration, the amount of glucose required to maintain euglycaemia equals whole body disposal of glucose, provided that there is no entry of glucose from the liver. Hepatic glucose production was measured by the isotope dilution technique using $\left[3-{ }^{3} \mathrm{H}\right]$ glucose (Amersham Inc., Amersham, Bucks, UK) $(99.6 \%$ purity) administered as a primed-constant $(0.25 \mu \mathrm{Ci} / \mathrm{min})$ infusion. The priming dose was adjusted for the degree of fasting hyperglycaemia. After a 150-min tracer equilibration period, the insulin infusion was started. Blood samples for determination of insulin and $\left[3{ }^{3} \mathrm{H}\right]$ glucose specific activity was obtained in the basal state and at 15-min intervals throughout the insulin clamp.

Indirect calorimetry was employed for $60 \mathrm{~min}$ in the basal state and during the last $60 \mathrm{~min}$ of the insulin clamp to estimate net rates of carbohydrate and lipid oxidation. A computerized, open-circuit system was used to measure gas exchange through a transparent plastic canopy (Deltatrac; Datex, Helsinki, Finland) [22]. The monitor has a precision of $2.6 \%$ for oxygen consumption and $1.0 \%$ for carbon dioxide production. Protein oxidation was calculated from the urinary urea nitrogen excretion obtained before and during the insulin clamp and corrected for changes in the urea pool [23].
Lean body mass was determined by the tritiated water technique [24]. Briefly, $40 \mu \mathrm{Ci}$ of tritiated water (Amersham) diluted in $0.9 \%$ $\mathrm{NaCl}$ was given as an i. v. injection. Blood samples for determination of tritiated water specific activity in plasma were drawn before and 80,100 and 120 min after the injection.

\section{Analytical determinations}

The plasma glucose concentration was measured in duplicate by the glucose oxidase method on a Beckman glucose analyzer II (Beckman Instruments, Fullerton, Calif., USA). S-insulin was measured by a double-antibody radioimmunoassay (Pharmacia, Uppsala, Sweden). S-triglycerides, s-cholesterol and HDL-cholesterol were determined by a commercially available enzymatic method (Boehringer Mannheim, FRG). Plasma NEFA were measured with the microfluorometric method described by Miles et al. [25]. $\left[3{ }^{3} \mathrm{H}\right]$ glucose specific activity was measured in duplicate on supernatant of $0.5 \mathrm{~mol} / \mathrm{l}$ perchloric acid extracts of plasma samples, after evaporation of radiolabelled water.

\section{Calculations}

Basal hepatic glucose production was calculated by dividing the $\left[3-{ }^{3} \mathrm{H}\right]$ glucose infusion rate by the steady-state plateau of $\left[3-{ }^{3} \mathrm{H}\right]$ glucose specific activity achieved during the last $30 \mathrm{~min}$ of the basal tracer infusion period. After administration of insulin and glucose, a non-steady-state condition in glucose specific activity exists, and the rate of glucose appearance was calculated by a two compartment model [26]. The infusion rate of cold glucose was integrated over 20 min intervals and subtracted from the total rate of glucose appearance to obtain hepatic glucose production rate. However, under conditions of hyperinsulinaemia and high glucose utilization, as present during a euglycaemic clamp, the two compartment model has been shown to underestimate glucose disposal [27]. The underestimation is probably due to expansion in the glucose pool which is attenuated at high glucose utilization rates. This will result in physiologically impossible negative hepatic glucose production rates. Negative rates of endogenous (hepatic) glucose production were occasional observed during the second hour of the insulin clamp. These values were taken to indicate that hepatic glucose production was completely suppressed. Total body glucose metabolism was calculated by adding the mean rate of hepatic glucose production (if a positive number) during the last $60 \mathrm{~min}$ of each insulin clamp step to the mean exogenous glucose infusion rate required to maintain euglycaemia during the same period. Non-oxidative glucose metabolism was calculated as the difference between total body glucose uptake and glucose oxidation, as determined by indirect calorimetry.

Substrate oxidation: Net glucose and lipid oxidation rates were calculated from indirect calorimetric measurements in the basal state and during the last $60 \mathrm{~min}$ of each insulin clamp. The constants to calculated glucose, lipid and protein oxidation have been reported previously [21]. Net lipid oxidation was converted to moles by dividing by the molecular weight of palmitate ( $m o l ~ w t .256$ ). At a non-protein respiratory quotient greater than 1.0 , the equation for the calculation of substrate oxidation remains valid; the remaining negative value for lipid oxidation is, in fact, equivalent to net fat synthesis.

Total body water was calculated from steady-state kinetic data assuming that $1 \mathrm{ml}$ of plasma contains $93 \%$ water. Lean body mass (LBM) was obtained by dividing total body water by 0.73 , since the LBM contains approximately $73 \%$ water. Fat mass was calculated as the difference between body weight and LBM.

\section{Statistical analysis}

Data are expressed as mean \pm SEM. The significance of differences between experiments were tested by Mann-Whitney U test using BMDP statistical package (Biomedical statistical program) [28]. Scheffés method was used for multiple comparisons. Correlations were tested by linear regression analyses. Since triglycerides were 
Table 1. Clinical characteristics of subjects

\begin{tabular}{|c|c|c|c|}
\hline & $\begin{array}{l}\text { Control } \\
\text { subjects }\end{array}$ & $\begin{array}{l}\text { Type } 2 \text { diabetic } \\
\text { patients without } \\
\text { hypertrigly- } \\
\text { ceridaemia }\end{array}$ & $\begin{array}{l}\text { Type } 2 \text { diabetic } \\
\text { patients with } \\
\text { hypertrigly- } \\
\text { ceridaemia }\end{array}$ \\
\hline $\begin{array}{l}\text { Number } \\
\text { (female/male) }\end{array}$ & $17(9 / 8)$ & $41(15 / 26)$ & $39(22 / 17)$ \\
\hline $\begin{array}{l}\text { Duration of diabetes } \\
\text { (years) }\end{array}$ & 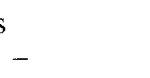 & $8 \pm 1$ & $9 \pm 1$ \\
\hline Age (years) & $56 \pm 3$ & $58 \pm 1$ & $59 \pm 1$ \\
\hline $\begin{array}{l}\text { Body mass index } \\
\left(\mathrm{kg} / \mathrm{m}^{2}\right)\end{array}$ & $26.0 \pm 0.5$ & $27.0 \pm 0.7$ & $27.4 \pm 0.5$ \\
\hline $\mathrm{Hb}_{1 \mathrm{c}}(\%)$ & $5.3 \pm 0.3$ & $7.8 \pm 0.2^{\mathrm{b}}$ & $8.0 \pm 0.2^{b}$ \\
\hline $\begin{array}{l}\text { Serum cholesterol } \\
(\mathrm{mmol} / \mathrm{l})\end{array}$ & $6.1 \pm 0.3$ & $5.9 \pm 0.2^{d}$ & $7.1 \pm 0.3^{a}$ \\
\hline $\begin{array}{l}\text { HDL-cholesterol } \\
(\mathrm{mmol} / \mathrm{l})\end{array}$ & $1.40 \pm 0.09$ & $1.36 \pm 0.05^{\circ}$ & $1.16 \pm 0.05^{\mathrm{b}}$ \\
\hline $\begin{array}{l}\text { Serum triglycerides } \\
(\mathrm{mmol} / \mathrm{l})\end{array}$ & $1.2 \pm 0.1$ & $1.4 \pm 0.1^{\mathrm{d}}$ & $3.2 \pm 0.2^{b}$ \\
\hline Fat mass (\%) & $33 \pm 2$ & $34 \pm 2$ & $37 \pm 2$ \\
\hline
\end{tabular}

${ }^{a} \mathrm{p}<0.05,{ }^{\mathrm{b}} \mathrm{p}<0.01$ vs control subjects;

${ }^{\mathrm{c}} \mathrm{p}<0.05,{ }^{\mathrm{d}} \mathrm{p}<0.01$ vs diabetic patients with hypertriglyceridaemia. Values are mean $\pm \mathrm{SEM}$

Table 2. Plasma glucose, serum insulin and non-esterified fatty acid concentrations (NEFA) measured in the basal state and during the clamp

\begin{tabular}{lccc}
\hline & $\begin{array}{l}\text { Control } \\
\text { subjects }\end{array}$ & $\begin{array}{l}\text { Type 2 diabetic } \\
\text { patients without } \\
\text { hypertrigly- } \\
\text { ceridaemia }\end{array}$ & $\begin{array}{l}\text { Type 2 diabetic } \\
\text { patients with } \\
\text { hypertrigly- } \\
\text { ceridaemia }\end{array}$ \\
\hline $\begin{array}{l}\text { Basal glucose } \\
\text { (mmol/1) }\end{array}$ & $5.1 \pm 0.5$ & $10.7 \pm 0.7^{\mathrm{a}}$ & $11.4 \pm 0.5^{\mathrm{a}}$ \\
$\begin{array}{l}\text { Clamp glucose } \\
\text { (mmol/) }\end{array}$ & $4.9 \pm 0.1$ & $5.7 \pm 0.1^{\mathrm{a}}$ & $6.0 \pm 0.1^{\mathrm{a}}$ \\
$\begin{array}{l}\text { Basal insulin } \\
\text { (pmol/1) }\end{array}$ & $37 \pm 5$ & $67 \pm 6^{\mathrm{c}}$ & $102 \pm 14^{\mathrm{a}}$ \\
$\begin{array}{l}\text { Clamp insulin } \\
\text { (pmol/1) }\end{array}$ & $568 \pm 30$ & $598 \pm 22$ & $643 \pm 23$ \\
$\begin{array}{l}\text { Basal NEFA } \\
(\mu \mathrm{mol} / \mathrm{l})\end{array}$ & $669 \pm 43$ & $676 \pm 30$ & $760 \pm 34$ \\
$\begin{array}{l}\text { Clamp NEFA } \\
(\mu \mathrm{mol} / 1)\end{array}$ & $71 \pm 10$ & $98 \pm 12^{\mathrm{b}}$ & $123 \pm 8^{\mathrm{a}}$ \\
\hline
\end{tabular}

${ }^{\mathrm{a}} \mathrm{p}<0.01$ vs control subjects; ${ }^{\mathrm{b}} \mathrm{p}<0.05$ vs diabetic patients with hypertriglyceridaemia; ${ }^{c} \mathrm{p}<0.01$ vs diabetic patients with hypertriglyceridaemia and control subjects.

Values are mean $\pm \mathrm{SEM}$

not normally distributed in the control subjects and the HTG patients, correlations were calculated after logarithmic transformation of the triglycerides. A $p$ value less than 0.05 was considered statistically significant.

\section{Results}

\section{Plasma glucose, NEFA and insulin concentrations}

Basal plasma glucose concentrations were elevated in the diabetic compared to the control subjects, but there was no difference between HTG and NTG patients (Table 2).
The HTG group displayed significantly elevated fasting insulin values when compared to the NTG group and control subjects $(p<0.01)$. Also the NTG group showed elevated basal insulin concentrations when compared to the control subjects $(p<0.01)$.

During the insulin clamp s-insulin was raised by approximately $530 \mathrm{pmol} / 1$ in all groups achieving similar steady-state insulin concentrations (Table 2). In the diabetic groups plasma glucose declined to approximately $6 \mathrm{mmol} / \mathrm{l}$ and was kept at that level during the last $60 \mathrm{~min}$ of the clamp (Table 2). Basal NEFA levels were similar in all groups, whereas the ability of insulin to suppress NEFA was impaired in the HTG group compared with the NTG group $(p<0.05)$ and control subjects $(p<0.01)$ (Table 2$)$.

\section{Glucose and lipid metabolism}

In the basal state both the HTG and NTG groups showed similiarly elevated rates of hepatic glucose production $\left(22.2 \pm 0.8\right.$ vs $21.1 \pm 0.8 \mu \mathrm{mol} \cdot \mathrm{kg} \mathrm{LBM}^{-1} \cdot \mathrm{min}^{-1}$ ) compared to the control subjects $\left(15.5 \pm 0.9 \mu \mathrm{mol} \cdot \mathrm{kg} \mathrm{LBM}^{-1}\right.$. $\left.\min ^{-1} ; p<0.001\right)$. Basal glucose oxidation was equal in both HTG and NTG patients $(9.3 \pm 0.6$ vs $9.0 \pm$ $0.5 \mu \mathrm{mol} \cdot \mathrm{kg} \mathrm{LBM}^{-1} \cdot \mathrm{min}^{-1}$ ), which did not differ from the control subjects $\left(10.0 \pm 0.5 \mu \mathrm{mol} \cdot \mathrm{kg} \mathrm{LBM}^{-1} \cdot \mathrm{min}^{-1}\right)$. However, basal lipid oxidation was increased in HTG compared to NTG patients $(5.5 \pm 0.2$ vs $4.8 \pm 0.2 \mu \mathrm{mol} \cdot \mathrm{kg}$ $\left.\mathrm{LBM}^{-1} \cdot \min ^{-1} ; p<0.05\right)$ and the control subjects $\left(4.3 \pm 0.3 \mu \mathrm{mol} \cdot \mathrm{kg} \mathrm{LBM}{ }^{-1} \cdot \mathrm{min}^{-1} ; p<0.01\right)$.

Both diabetic groups were insulin resistant when compared to the control subjects. However, in HTG patients total body glucose metabolism was impaired even when compared to NTG patients $(27.0 \pm 1.3$ vs $31.9 \pm$ $\left.1.6 \mu \mathrm{mol} \cdot \mathrm{kg} \mathrm{LBM}^{-1} \cdot \mathrm{min}^{-1} ; p<0.05\right)$.

During insulin stimulation there was a two-fold increase in glucose oxidation in all groups but compared to the healthy control subjects both diabetic groups showed impaired stimulation of glucose oxidation by insulin $\left(21.4 \pm 1.4 \mu \mathrm{mol} \cdot \mathrm{kg} \mathrm{LBM}{ }^{-1} \cdot \mathrm{min}^{-1} ; p<0.05\right)$. Glucose oxidation was similar in HTG and NTG patients $\left(16.9 \pm 0.8 \mathrm{vs} 17.2 \pm 0.7 \mu \mathrm{mol} \cdot \mathrm{kg} \mathrm{LBM}{ }^{-1} \cdot \mathrm{min}^{-1}\right)$.

Suppression of lipid oxidation by insulin was reduced in HTG compared with NTG patients $(3.5 \pm 0.2$ vs $\left.3.0 \pm 0.2 \mu \mathrm{mol} \cdot \mathrm{kg} \mathrm{LBM}{ }^{-1} \cdot \mathrm{min}^{-1} ; p<0.05\right)$ and control subjects $\left(1.8 \pm 0.4 \mu \mathrm{mol} \cdot \mathrm{kg} \mathrm{LBM}^{-1} \cdot \mathrm{min}^{-1} ; p<0.001\right)$. In addition, NTG patients showed enhanced rates of lipid oxidation compared to the control subjects $(p<0.01)$. The reduced total glucose uptake was due to impaired non-oxidative glucose metabolism in HTG (9.8 \pm

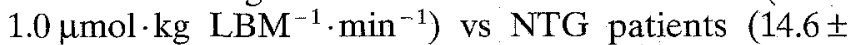
$1.4 \mu \mathrm{mol} \cdot \mathrm{kg} \mathrm{LBM}^{-1} \cdot \mathrm{min}^{-1} ; p<0.01$ ) (Fig. 2.). There was no statistically significant difference in the suppression of hepatic glucose production by insulin in HTG and NTG patients $\left(5.0 \pm 0.6\right.$ vs $\left.3.8 \pm 0.5 \mu \mathrm{mol} \cdot \mathrm{kg} \mathrm{LBM}^{-1} \cdot \mathrm{min}^{-1}\right)$. Nevertheless, the diabetic patients showed an enhanced rate of hepatic glucose production compared to the control subjects $\left(0.3 \pm 0.2 \mu \mathrm{mol} \cdot \mathrm{kg} \quad \mathrm{LBM}^{-1} \cdot \mathrm{min}^{-1}\right.$; $p<0.001$ ).

S-triglycerides correlated with lipid oxidation both in the basal state $(r=0.38, p<0.001)$ as well as during the 


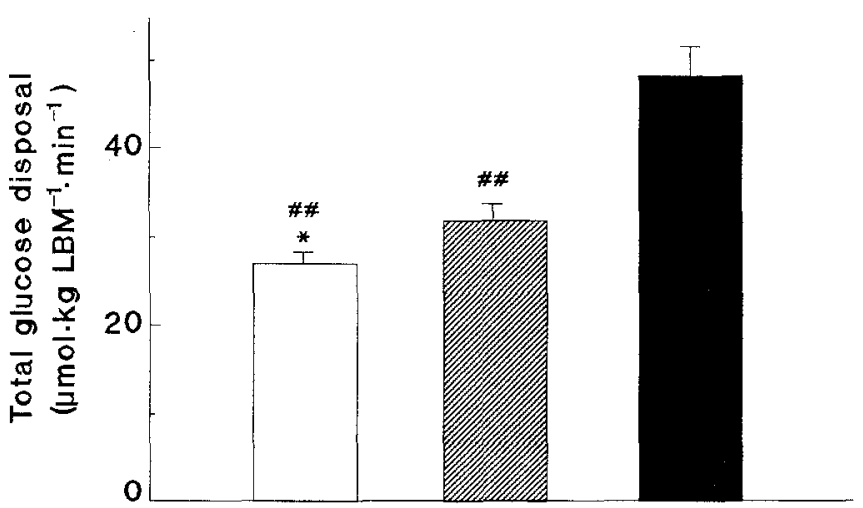

Fig. 1. Total glucose disposal during clamp in healthy control subjects ( $\boldsymbol{\square})$, in Type 2 diabetic patients with normal triglyceride levels ( $\approx$ ) and in Type 2 diabetic patients with hypertriglyceridaemia ( $\square)$. $* p<0.05$ vs patients with normal triglycerides. \# \# $p<0.01$ vs control subjects. LBM, Lean body mass

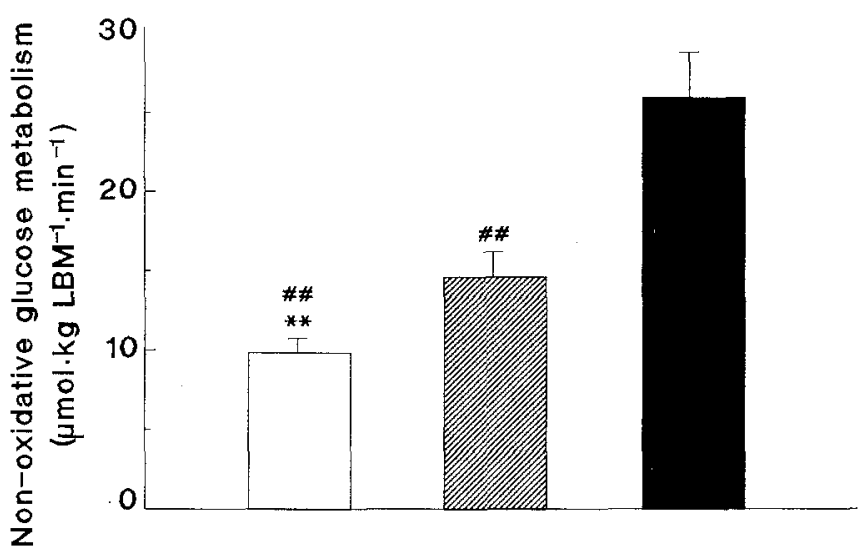

Fig. 2. Non-oxidative glucose metabolism in healthy control subjects (a), in Type 2 diabetic patients with normal triglyceride values ( $)$ and in Type 2 diabetic patients with hypertriglyceridaemia ( $\square$ ). ${ }^{* *} \mathrm{p}<0.01$ vs patients with normal triglycerides. \# \# $\mathrm{p}<0.01$ vs control subjects. LBM, Lean body mass

clamp $(r=0.51, p<0.001)$ (Fig. 3). There was an inverse correlation between s-triglycerides and basal glucose oxidation $(r=-0.26, p=0.01)$ and between basal glucose oxidation and basal lipid oxidation $(r=-0.46, p<0.001)$. Furthermore, there was an inverse correlation between total glucose disposal and s-triglycerides in all subjects (Fig.4). When groups were separately analysed, a correlation between the two variables was found both among the control subjects $(r=-0.62, p<0.01)$ and in the HTG and NTG groups combined $(r=-0.29, p<0.01)$. Consequently, glucose oxidation during the clamp correlated inversely with triglycerides in all subjects $(r=-0.34, p<0.001)$ and with lipid oxidation $(r=-0.59, p<0.001)$. Although insulinstimulated non-oxidative glucose metabolism correlated inversely with s-triglycerides in all subjects $(r=-0.37, p<0.001)$, no correlation was found in the different groups analysed separately. There was an inverse correlation between lipid oxidation and non-oxidative glucose metabolism during the clamp in all subjects $(r=-0.26, p=0.01)$. However, no correlations between the two variables were found when different groups were analysed separately.

\section{Energy expenditure}

Basal energy expenditure was increased in HTG compared with NTG patients $\left(105 \pm 2\right.$ vs $98 \pm 3 \mathrm{~J} \cdot \mathrm{kg} \mathrm{LBM}^{-1}$. $\left.\min ^{-1} ; p<0.05\right)$ and control subjects $\left(94 \pm 4 \mathrm{~J} \cdot \mathrm{kg} \mathrm{LBM}^{-1}\right.$ $\left.\cdot \min ^{-1} ; p<0.05\right)$. During insulin stimulation energy expenditure was similar in HTG and NTG patients (104 \pm 2 vs $100 \pm 3 \mathrm{~J} \cdot \mathrm{kg} \mathrm{LBM}^{-1} \cdot \mathrm{min}^{-1}$ ) as well as in control subjects $\left(99 \pm 4 \mathrm{~J} \cdot \mathrm{kg} \mathrm{LBM}{ }^{-1} \cdot \mathrm{min}^{-1}\right)$.

\section{Discussion}

In this study Type 2 diabetic patients characterized by hypertriglyceridaemia were found to be more insulin resistant than Type 2 diabetic patients with normal triglycerides. The further impairment in glucose utilization in the HTG patients was mainly accounted for by reduced non-oxidative glucose disposal, while glucose oxidation was similar in the two diabetic groups. Previously, several studies have shown associations between serum lipoprotein concentrations and glucose metabolism [11, 29-31], among others a negative correlation between triglycerides and glucose uptake has been observed. In the present study a negative correlation between total glucose disposal and s-triglyceride levels was found in all subjects.

There are several possible mechanisms that could explain the interaction between glucose disposal and triglycerides. Hypertriglyceridaemia may directly contribute to the impairment of insulin action. Plasma triglyceride-rich particles might influence the binding of insulin to its receptor [32] or interfere with early post-binding steps. In vivo, infusion of Intralipid has been shown to impair glucose disposal [14-18]. Whether this observation is due to increased levels of NEFA or triglycerides per se is a matter of dispute [14-18]. On the other hand, both hypertriglyceridaemia and impaired glucose metabolism could be a reflection of impaired insulin action.

In general, hypertriglyceridaemia might be caused by increased excretion of VLDL triglycerides from the liver or decreased clearance of triglycerides from plasma by reduced action of lipoprotein lipase [33]. Furthermore, it has been shown that suppression of lipolysis by insulin is reduced in HTG patients, thus providing excess NEFA for VLDL-triglyceride formation [11]. The elevated NEFA levels could also directly influence glucose metabolism. Since, NEFA are the major determinants of lipid oxidation [34] the HTG patients could be expected to have higher rates of lipid oxidation which might directly interfere with intracellular glucose metabolism.

In our study, the HTG patients showed elevated clamp NEFA concentrations as well as impaired suppression of lipid oxidation during insulin stimulation. Furthermore, there was a positive correlation between triglycerides and lipid oxidation both in the basal state as well as during the clamp in the entire study population indicating that hypertriglyceridaemia is associated with increased lipid oxidation. Does increased lipid oxidation cause decreased glucose uptake? Almost 30 years ago Randle and coworkers [13] introduced the concept of substrate competition between glucose and lipids, based on the finding that in- 


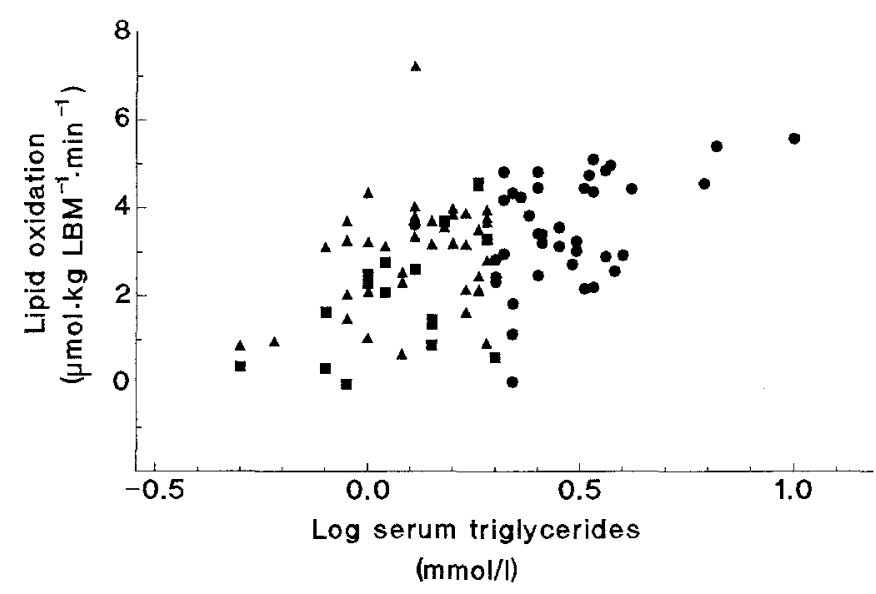

Fig. 3. Correlation between serum triglycerides and lipid oxidation during the last $60 \mathrm{~min}$ of the clamp in healthy control subjects ( $\boldsymbol{E}$ ), Type 2 diabetic patients with hypertriglyceridaemia ( ) and Type 2 diabetic patients with normal triglyceride levels $(\boldsymbol{\Delta})$. LBM, Lean body mass

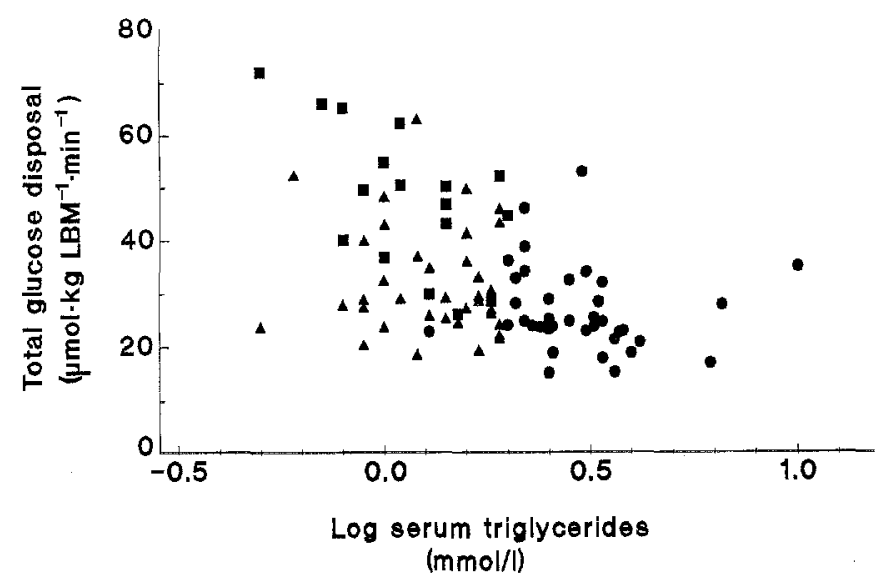

Fig. 4. Correlation between serum triglycerides and total glucose metabolism during the last $60 \mathrm{~min}$ of the clamp in healthy control subjects ( $\boldsymbol{\square}$ ), Type 2 diabetic patients with hypertriglyceridaemia (๑) and Type 2 diabetic patients with normal triglyceride levels (4) $(r=-0.48, p<0.001)$

creased lipid oxidation leads to decreased glucose oxidation in rat heart and diaphragm. These findings have been confirmed in human studies, showing that acute experimental enhancement of lipid oxidation leads to an impairment of glucose oxidation [15-18]. Although in the present study a negative correlation was found between glucose and lipid oxidation, the role of an activated Randle cycle as a cause of decreased insulin action in the HTG patients is challenged by the finding that glucose oxidation was not impaired in the HTG compared to NTG patients.

Is impaired non-oxidative glucose metabolism in Type 2 diabetic patients with hypertriglyceridaemia of genetic or metabolic origin? Serveral studies have suggested that NEFA might inhibit the non-oxidative pathway of glucose metabolism $[15,17,18]$. Supporting the in vivo data, increased NEFA oxidation has been demonstrated to inhibit glycogen synthase activity by causing dissociation of its subunits in vitro [35]. Accordingly, in the present study, the reduction of insulin action in the HTG patients was accounted for by impaired non-oxidative glucose metabolism. However, there was no correlation between triglycerides and non-oxidative glucose metabolism during the clamp in the HTG patients but an inverse correlation was observed between triglycerides and nonoxidative glucose metabolism, as well as between lipid oxidation and non-oxidative glucose metabolism, during the clamp for the entire study population.

However, this cross-sectional study design cannot differentiate between hypertriglyceridaemia inducing insulin resistance and both hypertriglyceridaemia and insulin resistance being co-existing corollaries of genetically impaired insulin action. Findings in a recent study by Shen et al. [36] supports the theory that both reduced glucose utilization and hypertriglyceridaemia are co-existing reflections of a genetically determined impairment of insulin action. In that study, lowering of triglycerides with gemfibrozil in Type 2 diabetic patients with hypertriglyceridaemia did not lead to significant improvement of the mean clearance rate of glucose. Since indirect calorimetry was not performed in the study, conclusions on possible effects of lowering triglycerides on nonoxidative glucose disposal cannot be drawn.

In conclusion, oxidative substrate competition between glucose and lipids does not explain decreased insulin action in Type 2 diabetic patients with hypertriglyceridaemia. The observed reduction in non-oxidative glucose metabolism may be genetically rather than metabolically determined.

Acknowledgements. This study was in part supported by grants from Finska Läkaresällskapet, the Sigrid Juselius Foundation and the Perklén Foundation.

\section{References}

1. Greenfield M, Kolterman O, Olefsky J, Reaven GM (1980) Mechanism of hypertriglyceridaemia in diabetic patients with fasting hyperglycaemia. Diabetologia 18: 441-446

2. Mancini MA, Rivellese A, Rubba P, Riccardi G (1980) Plasma lipoproteins in maturity onset diabetes. Nutr Metab 24: 65-71

3. Barret-Connor E, Grundy SM, Holdbrook MJ (1982) Plasma lipids and diabetes mellitus in adult community. Am J Epidemiol 115: 657-663

4. West KM, Ahuja MMS, Bennett PH et al. (1983) The role of circulating glucose and triglyceride concentrations and their interactions with other 'risk factors' as determinants of arterial disease in nine diabetic population samples from the WHO Multinational Study. Diabetes Care 6:575-578

5. Laakso M, Vuotilainen H, Sarlund H, Aro A, Pyörälä K, Penttilä I (1985) Serum lipids and lipoproteins in middle-aged non-insulin-dependent diabetics. Atherosclerosis 56: 271-281

6. Taskinen M-R (1990) Hyperlipidemia in diabetes. In: Betteridge DJ (ed) Lipid and lipid disorders. Baillière's clinical endocrinology and metabolism, vol 4. Baillière Tindall, London Philadelphia Sydney Tokyo Toronto, pp 743-775

7. DeFronzo RA (1988) The triumvirate: $\beta$-cell, muscle, liver. A collusion responsible for NIDDM. Diabetes 37: 667-687

8. Steiner G, Morita S, Vranic M (1980) Reistance to insulin but not to glucagon in lean human hypertriglyceridemics. Diabetes 29 : 899-905

9. Bazelmans J, Nestel PJ, Nolan C (1983) Insulin induced glucose utilization influences triglyceride metabolism. Clin Sci 64: 511516 
10. Reaven GM, Meheab K, Villaume C, Drouin P, Debry G (1983) Plasma glucose and insulin responses to oral glucose in nonobese subjects and patients with endogenous hypertriglyceridemia. Metabolism 32: 447-450

11.Yki-Järvinen H, Taskinen M-R (1988) Interrelationships among insulin's antilipolytic and glucoregulatory effects and plasma triglycerides in non-diabetic and diabetic patients with endogenous hypertriglyceridemia. Diabetes 37: 1271-1278

12. McKane WR, Stevens AB, Woods R, Andrews WJ, Henry RW, Bell PM (1990) The assessment of hepatic and peripheral insulin sensitivity in hypertriglyceridemia. Metabolism 39:1240-1245

13. Randle PJ, Garland PB, Hales CN, Newsholme EA (1963) The glucose fatty-acid cycle: its role in insulin sensitivity and the metabolic disturbances of diabetes mellitus. Lancet I: 785-789

14. Ferrannini E, Barrett EJ, Bevilacqua S, DeFronzo RA (1983) Effect of fatty acids on glucose production and utilization in man. $J$ Clin Invest 72: 1737-1747

15. Thiebaud D, DeFronzo RA, Jacot E et al. (1985) Effect of longchain triglyceride infusion on glucose metabolism in man. Metabolism 31: 1128-1136

16. Bevilacqua S, Buzzigoli G, Bonadonna R et al. (1990) Operation of Randle's cycle in patients with NIDDM. Diabetes 39: 383-389

17. Bonadonna R, Zych K, Boni C, Ferrannini E, De Fronzo RA (1989) Time dependence of the interation between lipid and glucose in humans. Am J Physiol 257: E49-E56

18. Boden G, Jadali F, White J et al. (1991) Effects of fat on insulinstimulated carbohydrate metabolism in normal men. J Clin Invest 88: 960-966

19. Alberti KGMM, Gries FA (1988) Management of non-insulindependent diabetes mellitus in Europe: a consensus view. Diabetic Med 5: 275-281

20. DeFronzo RA, Tobin JD, Andres R (1979) Glucose clamp technique: a method for quanifying insulin secretion and resistance. Am J Physiol 237: E214-E223

21. Ferrannini E (1989) The theoretical basis for indirect calorimetry: a review. Metabolism 37: 287-301

22. Meriläinen PT (1987) Metabolic monitor. Int J Clin Monitor Comput 4: 167-177

23. Tappy L, Owen O, Boden G (1988) Effect of hyperinsulinemia on urea pool size and substrate oxidation rates. Diabetes 37 : $1212-1216$

24. Coleman TG, Manning RD Jr, Norman A Jr et al. (1972) Dynamics of water-isotope distribution. Am J Physiol 223: 1371-1375

25. Miles JR, Glasscock J, Aikens J, Gerich J, Haymond M (1983) A microfluorometric method for the determination of free fatty acids in plasma. $\mathrm{J}$ Lipid Res 24: 96-99
26. Radziuk J, Norwich KH, Vranic M (1978) Experimental validation of measurements of glucose turnover in nonsteady state. Am J Physiol 234: E84-E93

27. Cobelli C, Mari A, Ferrannini E (1987) Non-steady state: error analysis of Steele's model and development for glucose kinetics. Am J Physiol 252: E679-E689

28. Dixon WJ (ed) (1988) BMDP statistical software manual. University of California Press, Berkeley

29. Abbott, WGH, Lillioja S, Young AA et al. (1988) Relationships between plasma lipoprotein concentrations and insulin action in an obese hyperinsulinemic population. Diabetes 36: 897-904

30. Garg A, Helderman JH, Koffler M, Ayuso R, Rosenstock J, Raskin P (1988) Relationship between lipoprotein levels and in vivo insulin action in normal young white men. Metabolism 37: 982987

31. Laakso M, Sarlund H, Mykkänen L (1990) Insulin resistance is associated with varying degrees of glucose tolerance. Arteriosclerosis 10: 223-231

32. Bieger WP, Michel G, Barwich D, Bhiel K, Wirth A (1984) Diminished insulin receptors on monocytes and erythrocytes in hypertriglyceridemia. Metabolism 33: 982-987

33. Grundy SM (1984) Pathogenesis of hypertriglyceridemia in man. In: Carlsson LA, Olsson AG (eds) Treatment of hyperlipoproteinemia. Raven Press, New York, pp 21-34

34. Groop L, Bonadonna R, Shand M, Petrides A, DeFronzo RA (1991) Role of free fatty acids and insulin in determining free fatty acid and lipid oxidation in man. J Clin Invest 87: 83-89

35. Wititsuwannakul D, Kim J (1977) Mechanism of palmityl coenzyme A inhibition of liver glycogen synthase. J Biol Chem 252: 7812-7817

36. Shen D-C, Fuh MTT, Shieh S-M, Chen Y-DI, Reaven GM (1991) Effect of gemfibrozil treatment in sulfonylurea-treated patients with non-insulin-dependent diabetes mellitus. J Clin Endocrinol Metab 73: 503-510

Received: 5 February 1992

and in revised form: 31 July 1992

Dr. L. Groop

Fourth Department of Medicine

Helsinki University Hospital

Unioninkatu 38

SF-00170 Helsinki

Finland 